\title{
Stubborn rectal prolapse in systemic sclerosis
}

\author{
Sven Petersen ${ }^{1}$, Alexander Tobisch ${ }^{1}$, Gero Puhl ${ }^{1}$, Ina Kötter ${ }^{2}$, Uwe Wollina ${ }^{3}$ \\ ${ }^{1}$ Department of General-, Visceral- and Vascular Surgery, Asklepios Hospital Altona, Hamburg, Germany \\ 2Department of Rheumatology, Clinical Immunology and Nephrology, Asklepios Hospital Altona, Hamburg, Germany \\ ${ }^{3}$ Department of Dermatology and Allergology Hospital Dresden-Friedrichstadt, Dresden, Germany
}

\begin{abstract}
Systemic sclerosis (SSc) is an autoimmune connective tissue disorder. Anorectal involvement might typically cause fecal incontinence and rarely rectal prolapse. Here we report three female patients, who were admitted with a mean history of 10 years suffering from SSc. All patients presented with the initial symptom of anal incontinence, in all cases this was associated with rectal intussusception or rectal prolapse. The three women faced prolapse recurrence, independent of the initial procedure. After surgical removal of the prolapse, the incontinence remained.

In SSc rectal prolapse syndrome might occur at an earlier age, and a primary prolapse of the ventral aspect of the rectal wall seems to be typical for this disease. If patients with prior diagnosis of SSC appear with third degree of fecal incontinence, it is suspected to be associated with rectal prolapse. The prolapse recurrence rate after surgery in SSc patients is high.
\end{abstract}

Key words: systemic sclerosis, rectal prolapse, incontinence.

\section{Introduction}

Systemic sclerosis (SSC) is an autoimmune connective tissue disorder that affects various body parts, particularly skin, digestive tract, lungs and heart [1, 2] Digestive complications such as esophagus sequelae are common in SSc and nearly $90 \%$ of patients with SSc show at least one upper Gl symptom [3]. Anorectal infringement is also frequent in SSc patients (50-70\%), often resulting in bowel incontinence and additional anorectal disorders [4]. Anorectal involvement might typically cause fecal incontinence and rarely rectal prolapse. If a prolapse occurs it is a substantial problem, especially in elderly patients. In these cases, prolapse is the leading problem in the so-called prolapse syndrome, which is a combination of prolapse as well as constipation and fecal incontinence [5]. The increased viscosity of secretion and associated constipation might be the underlying condition leading to heavy straining [6]. The majority of patients facing rectal prolapse are aged eighty years and older [7].
In order to present the variety and harmful character of rectal prolapse in combination with SSc, three cases are provided in this series.

\section{Case reports}

\section{Patient 1}

A 65 year-old woman presented in March 2014 with a third degree rectal prolapse and third degree incontinence. She was suffering from a limited form of cutaneous SSc since 2009 with symptoms of Raynaud's syndrome, acral erosions and puffy fingers. No esophagus or other Gl tract involvement was observed, antibody profile was ANA HEP2 positive and CENP-B positive. At the time of initial treatment of rectal prolapse, medication with methotrexate was given.

In March 2014 she underwent laparoscopic anterior rectal resection and rectopexy with resection of $55 \mathrm{~cm}$ of sigmoid colon.

In September 2014 the patient reported a prolapse recurrence, the clinical examination showed an isolat- 
ed ventral recurrence (Fig. 1). She underwent transanal rectal full wall resection using Altemeier technique. The resection weight was $14 \mathrm{~g}$ only.

In April 2015 the patient received sacral nerve stimulation for third degree incontinence. Prior to this, testing for sacral nerve modulation was positive and fecal incontinence improved.

In May 2015 a second rectal prolapse reoccurred. At this time the patient underwent an extracorporeal rectal resection, so called Altemeier procedure again. In contrast to the procedure in 2014, this time a circular resection was necessary.

At the last follow-up in June 2016, there was no evidence of prolapse recurrence, but third degree incontinence with urge symptoms remained.

\section{Patient 2}

An 82 year-old woman was diagnosed for ventral third degree rectal prolapse and third degree incontinence in May 2014. SSc was diagnosed in 2009 as diffuse systemic cutaneous form with a modified Rodnan skin score of 15/51 (2012) and a Raynaud's syndrome. In addition, motility problems of the esophagus and distended stomach as evidence of delay gastric emptying, in the absence of a mechanical obstruction, were diagnosed. Since 2009, patient received methotrexate treatment. Antibody status at the first time of surgery was ANA positive, SCL-70 positive.

The patient underwent extra corporal rectal resection of the ventral aspect of the rectum in so-called Transtar technique. The specimen weight was $16 \mathrm{~g}$.

In November 2015 the patient was readmitted with a circumferential recurrence. At this time she underwent extra corporal rectal resection in Altemeier technique.

The last follow-up examination showed no evidence of prolapsed recurrence, but third degree incontinence persists.

\section{Patient 3}

A 72 year-old woman, first admission in 2012, with rectal mucosa prolapses associated with an obstructed defecation and a cystocele (Figs. 2-4) in combination with third degree incontinence. The prolapse was treated by a transanal rectal resection (STARR) of $6 \mathrm{~cm}$ rectal height. At that time she was suffering limited systemic cutaneous sclerosis, first diagnosed in 1992, with dermatosclerosis, cutaneous calcinosis, Raynaud syndrome, modified Rodnan Skin score was 24/51 (2012). The patient was also suffering from gastro-esophageal reflux disease (GERD), first degree Barrett esophagus, hiatal hernia and gastric dysmotility. According to the antibody status, only ANA with centromere fluorescence pattern was positive. Also this patient suffered from arterial pul-

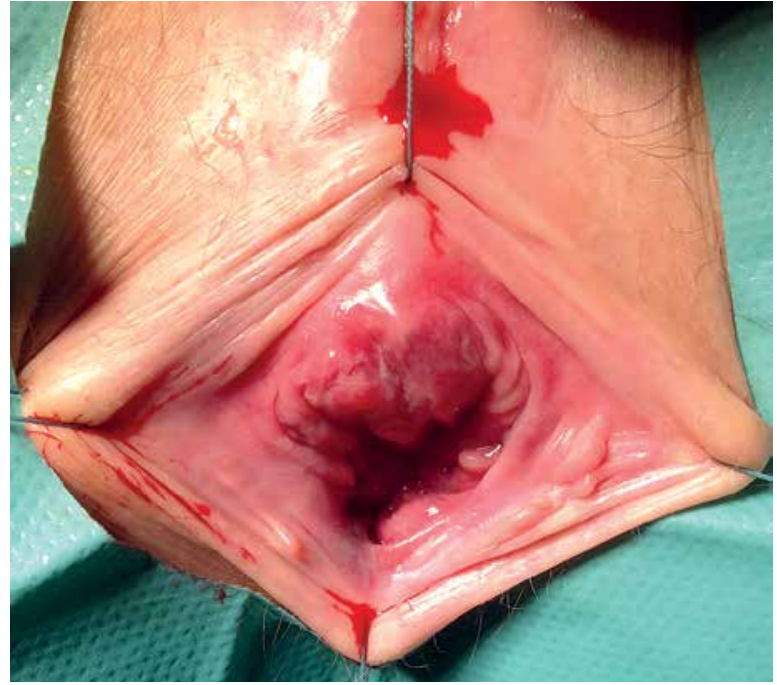

Fig. 1. Prolapsing ventral rectal wall in SSc patient.

monary hypertension (Dana Point Classification Stage 1) and since 2009 the patient have been received dual endothelin receptor antagonist - bosentan in dose $125 \mathrm{mg}$.

In April 2014 a ventral recurrences was diagnosed and the patient underwent partial extra-corporal full thickness rectal resection in Altemeier technique.

In March 2015 the patient faced a second recurrence and at this time a circular Altemeier procedure was necessary. However, at this time only a limited resection was possible, due to the fixation of the dorsal aspect of the rectal wall.

Finally in May 2016, again a third degree rectal prolapse was visible. The patient underwent a third Altemeier procedure. This time $27 \mathrm{~cm}$ of sigmoid colon was resected and transanal anastomosis was sutured.



Fig. 2. MRI Defecography: sagittal section of the pelvis in SSc patient: large distension of the bladder and distended rectum. 


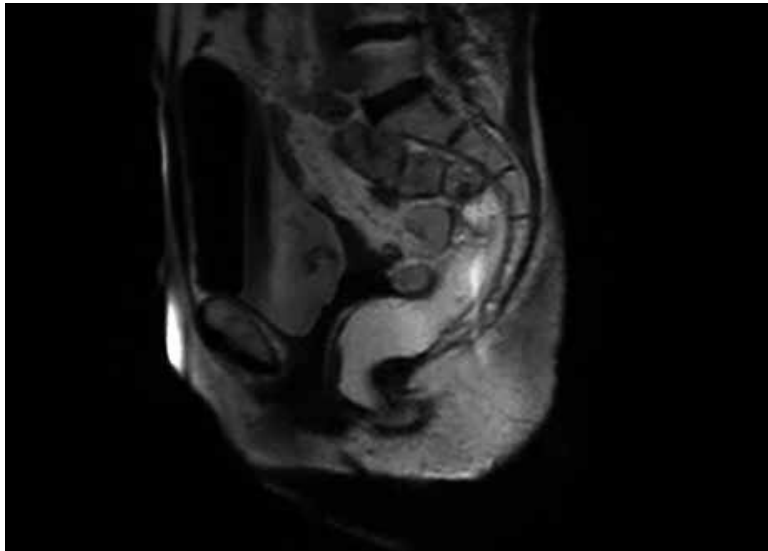

Fig. 3. MRI Defecography: sagittal section of the pelvis in SSc patient: at beginning of defecation.

The last follow-up examination showed no evidence of prolapsed recurrence, but persisting third degree incontinence.

\section{Discussion}

Here we presented three cases of SSc patients with third degree rectal prolapse focusing on the specific dilemma of anorectal function in SSc.

Overall GI affection is seen in about $90 \%$ of patients with SSC $[3,6]$. Anorectal involvement was reported in $50 \%$ to $70 \%$ of SSc patients [8]. Anorectal dysfunction might be closely linked to esophageal involvement in SSc [9]. A typical expression of SSc in the lower GI tract is a combination of constipation, fecal incontinence and rectal prolapse $[6,10]$, which is also known as rectal prolapse syndrome in patients with non-SSc rectal prolapse.

In general, pathophysiology of rectal prolapse and concomitant incontinence is closely related to disordered collagen synthesis and dystrophic muscle and damage during childbirth. In SSc, the pathophysiology of fecal incontinence is most likely related to neuropathy as suggested by absent rectal inhibition reflex and higher anal sensory threshold and is related less so to sphincter atrophy and rectal fibrosis in contrast to gut dismotility $[9,11]$. The choline-associated motility-mechanism is disturbed. A participation of the colon is important as already mentioned with constipation, frequently associated with fecal incontinence.

Thoua et al. [12] reported that patients with SSc have a thin and atrophic internal anal sphincter, which suggests that internal sphincter atrophy develops even in asymptomatic patients and this may be amenable to treatment with sacral neuromodulation.

Lower voluntary squeeze pressure in incontinent SSc patients and external anal sphincter (EAS) sonograph-



Fig. 4. MRI Defecography: sagittal section of the pelvis in SSc patient: at the end of defecation the pelvis is lowered and a wide rectocele is shown.

ic abnormalities only in SSc patients with incontinence suggest that the EAS is of major importance for fecal continence in SSc patients. The finding of an increased fiber density further supports involvement of EAS in SSc and could indicate previous nerve injury with consequent incomplete re-innervation. SSc patients with incontinence also have a thin internal anal sphincter and a low resting pressure. Centromeric antibodies and in particular vascular disease have been identified as possible risk factors for anal incontinence among SSC patients [13]. It is unclear whether ischemic events are responsible for the nerve damage or not [14].

In conclusion, both nerval and vascular factors are involved in Gl involvement in SSc. Nevertheless, SSc patients show impaired anorectal pressures, sensations, and rectal compliance [15].

In addition to the findings on the mechanisms of incontinence and constipation, the data presented here potentially might suggest clinical pattern of rectal prolapse in SSc, with the following clinical implication.

In patients with SSc, rectal prolapse syndrome possibly might occur at an earlier age compared to patients with non-SSc prolapse. Various publications showed a mean age of patients with third degree rectal prolapse at the age of 80 years and above $[5,7]$.

A primary prolapse of the ventral aspect of the rectal wall was the first symptom of SSc related prolapse in this group. This aspect was not reported so far. The question arises whether this ventral prolapse is due to excessive straining, caused by high viscosity of stool in SSc patients.

In our SSc patients, the recurrence rate after surgery is high. In contrast to other non-SSc rectal prolapse patients, where recurrence rate after surgery, independent to the surgical technique for prolapse repair, should be 
significant lower. E.g. for transanal resections a recurrence rate of $10 \%$ is a reasonable recurrence rate $[7,16-$ 18]. The question of surgical access to rectal prolapse in patients with SSc does most likely not differ from other patients with non-SSc rectal prolapse. A Cochrane-analysis was unable to identify or refute clinically important differences between the alternative surgical operations [19]. Thus, transabdominal as well as transanal access for surgical repair are reasonable in SSc patients [4].

Conflict of interest: the author received a grant supply from and serves as a consultant to Ethicon, Johnson \& Johnson Medical $\mathrm{GmbH}$, and served as a consultant to Touchstone International Medical Science.

\section{References}

1. Barsotti S, Stagnaro C, d'Ascanio A, et al. One year in review 2016: systemic sclerosis. Clin Exp Rheumatol 2016; 34 Suppl 100: 3-13.

2. Gyger G, Baron M. Systemic Sclerosis: Gastrointestinal Disease and Its Management. Rheum Dis Clin North Am 2015; 41: 459-473.

3. Weston S, Thumshirn M, Wiste J, et al. Clinical and upper gastrointestinal motility features in systemic sclerosis and related disorders. Am J Gastroenterol 1998; 93: 1085-1089.

4. Leighton JA, Valdovinos MA, Pemberton JH, et al. Anorectal dysfunction and rectal prolapse in progressive systemic sclerosis. Dis Colon Rectum 1993; 36: 182-185.

5. Heitland W. Der Rektumprolaps des Erwachsenen. Chirurg 2004; 75: 882-889.

6. Butt $\mathrm{S}$, Emmanuel A. Systemic sclerosis and the gut. Expert Rev Gastroenterol Hepatol 2013; 7: 331-339.

7. Sailer M, Bonicke L, Petersen S. Chirurgische Therapieoptionen beim Rektumprolaps - Indikation, Technik und Ergebnisses. Zentralbl Chir 2007; 132: 350-357.

8. Franck-Larsson K, Graf W, Ronnblom A. Lower gastrointestinal symptoms and quality of life in patients with systemic scle- rosis: a population-based study. Eur J Gastroenterol Hepatol 2009; 21: 176-182.

9. Luciano L, Granel B, Bernit E, et al. Esophageal and anorectal involvement in systemic sclerosis: a systematic assessment with high resolution manometry. Clin Exp Rheumatol 2016; 34 Suppl 100: 63-69.

10. Thoua NM, Bunce C, Brough G, et al. Assessment of gastrointestinal symptoms in patients with systemic sclerosis in a UK tertiary referral centre. Rheumatology (Oxford) 2010; 49: 1770-1775.

11. Thoua NM, Abdel-Halim M, Forbes A, et al. Fecal incontinence in systemic sclerosis is secondary to neuropathy. Am J Gastroenterol 2012; 107: 597-603.

12. Thoua NM, Schizas A, Forbes A, et al. Internal anal sphincter atrophy in patients with systemic sclerosis. Rheumatology (Oxford) 2011; 50: 1596-1602.

13. Bartosik I, Andreasson K, Starck M, et al. Vascular events are risk factors for anal incontinence in systemic sclerosis: a study of morphology and functional properties measured by anal endosonography and manometry. Scand J Rheumatol 2014; 43: 391-397.

14. Franck-Larsson K, Graf W, Eeg-Olofsson KE, et al. Physiological and structural anorectal abnormalities in patients with systemic sclerosis and fecal incontinence. Scand J Gastroenterol 2014; 49: 1076-1083.

15. Sallam HS, McNearney TA, Chen JZ. Anorectal motility and sensation abnormalities and its correlation with anorectal symptoms in patients with systemic sclerosis: a preliminary study. ISRN Gastroenterol 2011; 2011: 402583.

16. Matzel KE, Heuer S, Zhang W. Rektumprolaps. Abdominelles oder lokales Vorgehen. Chirurg 2008; 79: 444-451.

17. Scherer R, Marti L, Hetzer FH. Perineal stapled prolapse resection: a new procedure for external rectal prolapse. Dis Colon Rectum 2008; 51: 1727-1730.

18. Petersen S, Schinkel B, Jurgens S, et al. Impact of prolapse mass on Contour Transtar technique for third-degree rectal prolapse. Int J Colorectal Dis 2013; 28: 1027-1030.

19. Tou S, Brown SR, Nelson RL. Surgery for complete (full-thickness) rectal prolapse in adults. Cochrane Database Syst Rev 2015; CD001758. 